\title{
Identifikasi Rekahan Dangkal Akibat Aktivitas Lumpur Sidoarjo di Kecamatan Tanggulangin - Kabupaten Sidoarjo Menggunakan Metode Ground Penetrating Radar (GPR)
}

\author{
Ilham Adi, Firman Syaifuddin dan Dwa Desa Warnana \\ Jurusan Teknik Geofisika, Fakultas Teknik Sipil Dan Perencanaan, Institut Teknologi Sepuluh Nopember (ITS) \\ Jl. Arief Rahman Hakim, Surabaya 60111 Indonesia \\ e-mail:dwa_desa@geofisika.its.ac.id
}

\begin{abstract}
Abstrak-Rencana pengeboran sumur gas baru PT. Lapindo Brantas di Tanggulangin, Sidoarjo dinilai beresiko karena lokasinya yang dekat dengan pusat semburan yang telah rusak dan masih sangat rawan, sehingga masih ada potensi keluarnya semburan di area tanggul dan sekitarnya jika dibor. Selain itu, aktivitas lumpur sidoarjo menyebabkan kondisi bawah permukaan di daerah penelitian menjadi rentan terhadap resiko rekahan dan penurunan tanah. Oleh sebab itu, perlu dilakukan penelitian tentang kondisi bawah permukaan dangkal menggunakan metode Ground Penetrating Radar (GPR) yang bertujuan untuk mendeteksi rekahan dangkal yang berada di sekitar daerah rencana pengeboran. Metode GPR dipilih karena dapat memetakan kondisi bawah permukaan yang dangkal secara terperinci dengan resolusi yang tinggi. Berdasarkan hasil penelitian ini, diketahui bahwa pada daerah rencana pengeboran terdapat banyak rekahan berpola radial dengan arah barat daya-timur laut dan rekahan berpola melingkar (circular) yang berarah barat laut-tenggara. Kondisi tersebut membuat daerah bawah permukaan di sekitar lokasi rencana pengeboran menjadi tidak stabil dan berisiko karena dapat menyebabkan penurunan tanah di daerah sekitar dan dikhawatirkan dapat memperluas semburan lumpur panas pada daerah penelitian.
\end{abstract}

Kata Kunci-Bawah Permukaan, GPR, Lumpur Panas, Rekahan.

\section{PENDAHULUAN}

$\mathrm{P}$ ADA awal tahun 2016, PT. Lapindo Brantas berencana melakukan pengeboran sumur gas baru di daerah Tanggulangin, Sidoarjo. Lokasi pengeboran ini berjarak sekitar tiga kilometer dari pusat semburan utama, sehingga dinilai memiliki resiko yang tinggi yang dapat mengakibatkan meluasnya semburan lumpur panas ke daerah tersebut. sehingga perlu dilakukan penelitian dengan menggunakan metode geofisika untuk mengetahui kondisi bawah permukaan dangkal seperti rekahan pada daerah pengeboran sumur gas baru tersebut.

Penelitian ini bertujuan untuk mengidentifikasi posisi dan pola rekahan pada daerah penelitian sehingga dapat digunakan untuk mengetahui pengaruh rekahan yang ada terhadap kondisi tanah di daerah pengeboran sumur gas baru sehingga dapat diketahui tingkat resiko yang timbul jika pengeboran sumur gas baru milik PT Lapindo Brantas tetap dilakukan.

Metode geofisika yang cocok untuk memetakan rekahan adalah Ground Penetrating Radar (GPR), karena mampu memetakan kondisi bawah permukaan yang dangkal secara terperinci dengan resolusi yang tinggi [1]. Pada penelitian ini, kedalaman yang dapat dipertanggungjawabkan adalah 35 meter.

\section{METODE PENELITIAN}

\section{A. Lokasi Penelitian}

Lokasi penelitian ini berada di sekitar daerah pengeboran sumur gas baru di Tanggulangin, Sidoarjo, Jawa Timur. Dimana titik hijau merupakan lokasi rencana pengeboran sumur gas baru Lapindo (TA 6 dan TA 10).

\section{B. Pengolahan Data}

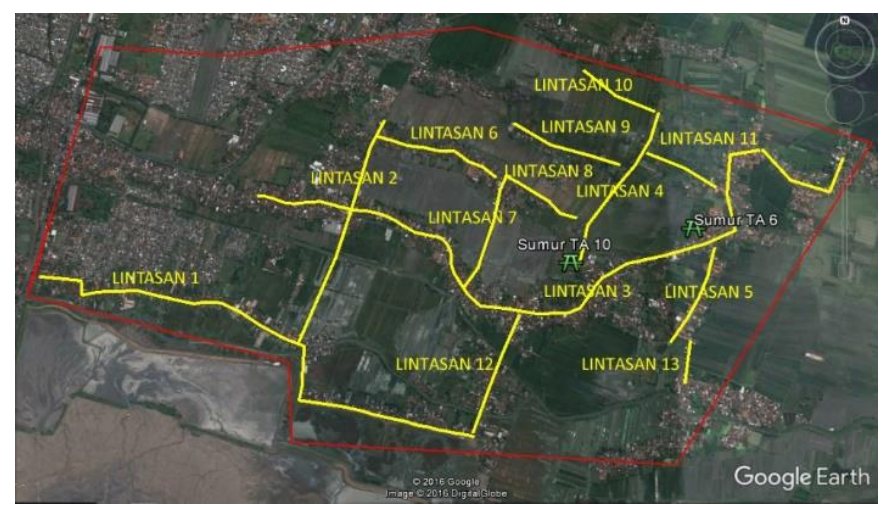

Gambar. 1. Lintasan pengukuran GPR (lintasan 1-5) dan lokasi rencana pengeboran (Sumur TA 6 dan 10) 
Data GPR tersebut kemudian diolah berdasarkan diagram alir sebagai berikut.

Adjust Signal Position digunakan untuk menghilangkan

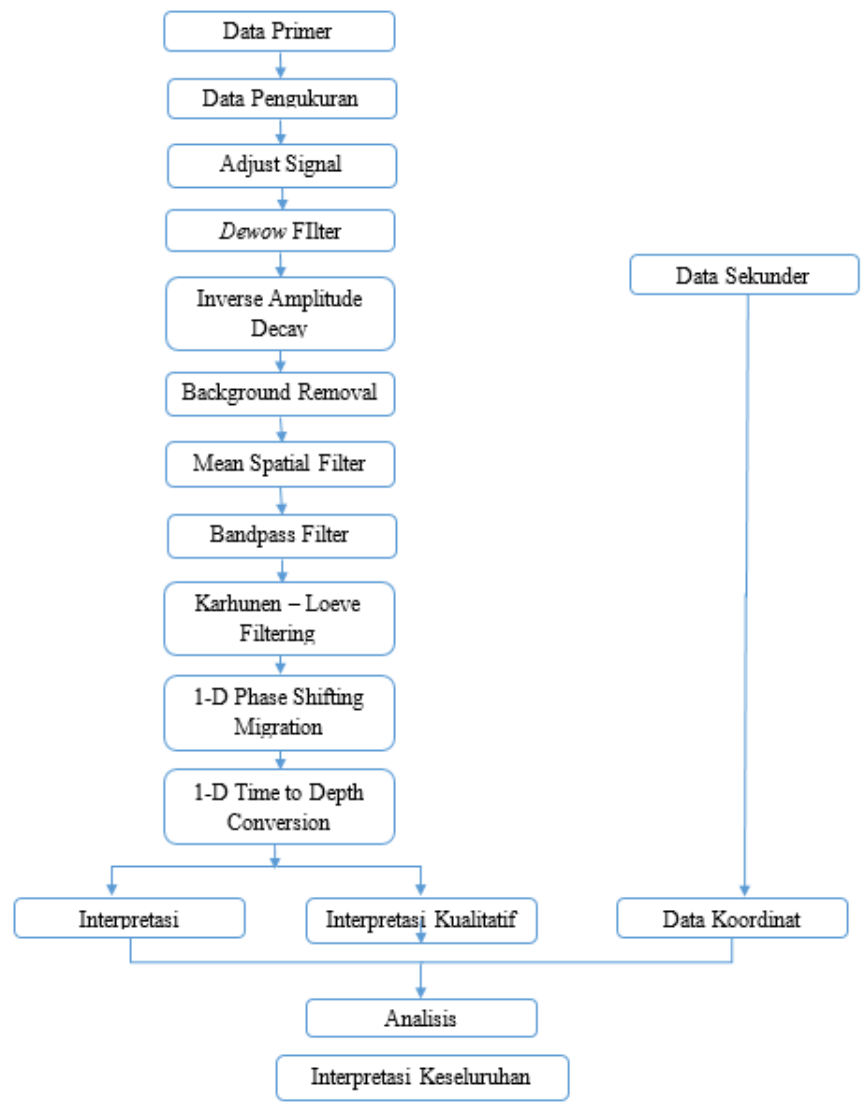

Gambar. 2. Diagram Alir Pengolahan Data GPR

waktu jeda antara sinyal yang terbaca pertama hingga sampai pada kontras lapisan permukaan tanah. Poses filteing digunakan untuk menghilangkan berbagai frekuensi lateral dan horizontal. Proses inverse amplitude decay dilakukan untuk meningkatkan gain, peningkatan gain dilakukan karena sinyal radar sangat cepat teratenuasi ketika menjalar ke dalam permukaan bumi, sehingga sinyal dari kedalaman yang lebih tinggi menjadi sangat kecil/lemah dan informasi yang berasal dari sinyal lemah tersebut tidak begitu terlihat. Proses 1-D Phase Shifting Migration ini digunakan untuk memindahkan data GPR ke posisi yang benar secara horizontal maupun vertikal. Ketidakpastian posisi ini disebabkan oleh efek difraksi yang terjadi ketika gelombang elektromagnetik mengenai ujung atau puncak suatu diskontinuistas akibat perbedaan struktur geologi seperti sesar atau lipatan, dan 1-D Time to Depth Conversion merupakan proses konversi data GPR dari domain waktu menjadi domain kedalaman. Hal ini dilakukan untuk mendapatkan kedalaman sebenarnya dari data penampang.

\section{HASIL DAN DISKUSI}

\section{A. Identifikasi Rekahan}

Parameter pertama yang digunakan sebagai dasar penentuan lokasi dan arah rekahan adalah pola diskontinuitas structural yang dapat diamati secara langsung pada radargram serta data dari kondisi di lapangan saat pengambilan data, seperti adanya jembatan atau sawah. Parameter kedua adalah struktur geologi di lokasi penelitian sehingga dapat diketahui pola dan arah rekahan pada struktur geologi tersebut, di mana struktur geologi akan menjadi parameter untuk mengonfrmasi rekahan yang ditentukan oleh parameter diskontinuitas. Struktur yang menembus (piercement structure) yang aktif memiliki pola rekahan yang circular (melingkar) dan radial (menjari) dengan model ditunjukan oleh gambar 3 [6]:

Struktur geologi di Lumpur Sidoarjo (Lusi) dapat dianalogikan memiliki model yang serupa dengan Gambar 4 karena interpretasi data seismik yang melintasi lokasi semburan Lumpur Sidoarjo menunjukkan bahwa terdapat struktur menembus (piercement structure) yang kompleks sebagai struktur geologi Lumpur Sidoarjo [2].
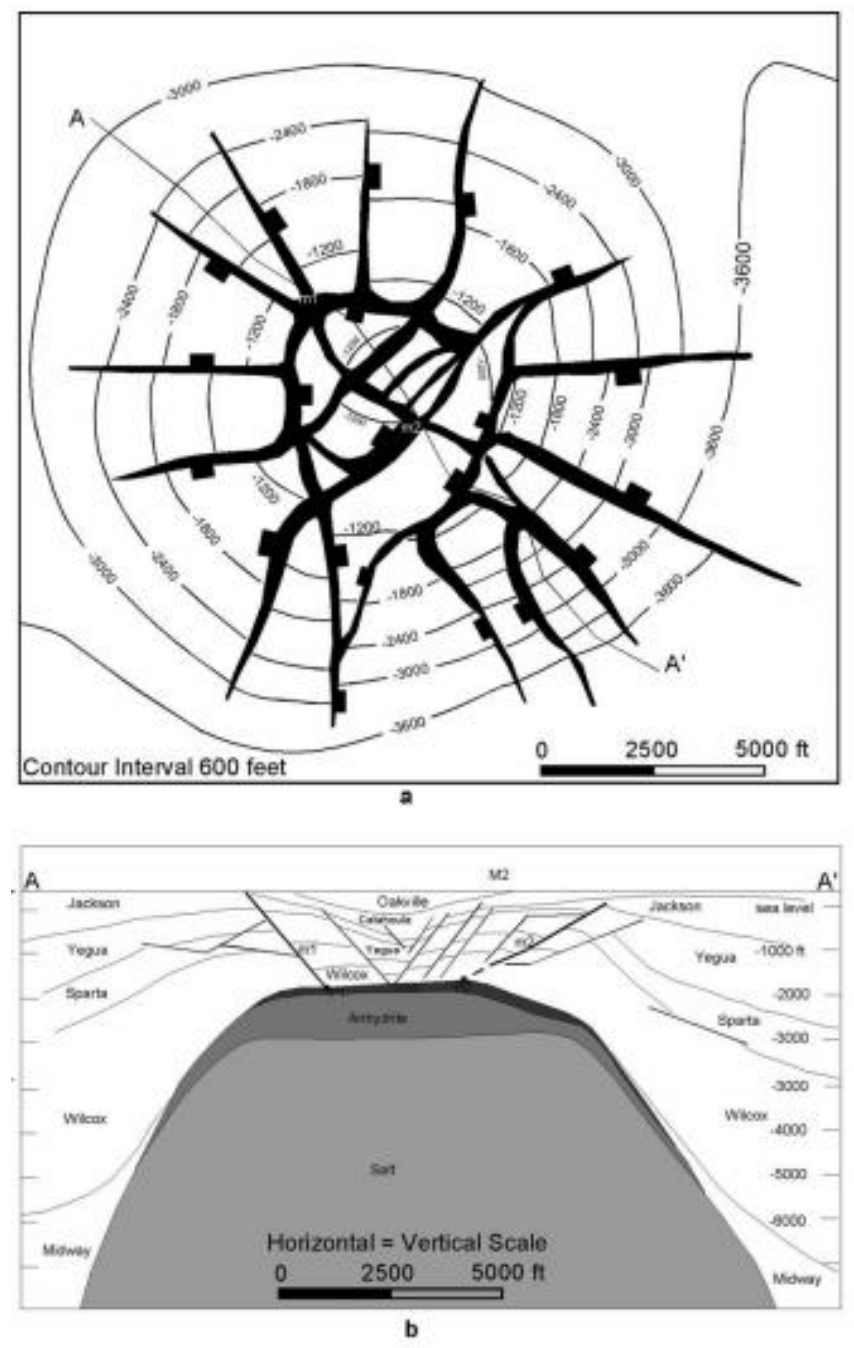

Gambar. 3. (a) Contoh pola rekahan pada struktur menembus aktif (active piercement structures) tampak atas, (b) penampang bawah permukaan dari pola rekahan pada stuktur menembus aktif (active piercement structures) (Yin \& Jr, 2004).

\section{B. Analisis Pola Rekahan}

Lintasan yang berorientasi barat timur dan berada di utara pusat semburan Lusi, dapat mengidentifikasi rekahan pada jalur 
selatan-utara, tenggara-barat laut, dan barat daya-timur laut yang akan tampak pada radargram. Lintasan yang berorientasi selatan utara dan berada di utara pusat semburan Lusi, hanya akan mengidentifikasi rekahan yang berada pada jalur barat hingga timur.

Apabila rekahan pada orientasi yang sama dihubungkan dan di-overlay dengan peta lapisan bawah permukaan, maka terlihat suatu pola rekahan yang terbagi menjadi dua tipe pola rekahan, yaitu pola rekahan circular yang berpola melingkari pusat semburan Lusi dan pola rekahan radial atau menjari, yang mengarah ke pusat semburan Lusi, seperti terlihat polanya pada Gambar 4. Rekahan pada jalur barat daya-timur laut dan berada pada sisi utara pusat stuktur merupakan rekahan jenis radial yang menjalar memanjang relatif lurus dari pusat semburan. Rekahan yang tampak berada pada arah barat laut-tenggara merupakan rekahan circular yang menyebar dan mengelilingi pusat semburan.

\section{KESIMPULAN DAN SARAN}

\section{A. Kesimpulan}

Kesimpulan yang didapat dari penelitian ini adalah:

1) Rekahan terlihat pada seluruh radargram lintasan pada

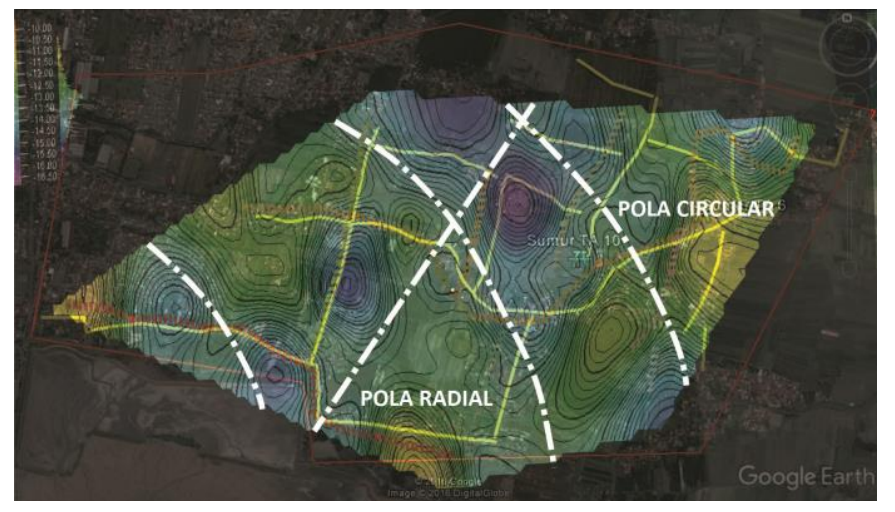

Gambar. 4. Hasil plotting rekahan teridentifikasi ke dalam peta permukaan dan di-overlay dengan peta lapisan bawah permukaan, membentuk pola rekahan radial dan circular.

kedalaman 0-36 meter dengan panjang rekahan 9-61 meter.

2) Terdapat dua pola rekahan, yaitu rekahan berarah barat daya-timur laut dan berada di utara pusat semburan merupakan jenis rekahan radial yang menjalar lurus atau menjari dari pusat semburan; dan rekahan berarah barat laut-tenggara merupakan jenis rekahan circular yang menyebar seperti lingkaran dari pusat semburan.

\section{B. Saran}

Saran yang dapat diberikan berdasarkan hasil dan kesimpulan untuk membangun hipotesa-hipotesa selanjutnya adalah:

1) Untuk mendapatkan hasil yang lebih baik dan akurat terhadap sebaran dan pola rekahan, lintasan pengukuran dapat diperbanyak dengan berbagai variasi orientasi sehingga dapat mengidentifikasi lebih banyak variasi arah rekahan, karena faktor keberhasilan identifikasi rekahan adalah arah pengukuan yang tepat dan sesuai struktur geologi daerah penelitian.

2) Perlu dilakukan penelitian dengan metode geofisika yang lain sebagai pembanding hasil posisi dan letak dari rekahan.

\section{DAFTAR PUSTAKA}

[1] Handoko, Godwin, K, B., \& U, H. (2010). Penafsiran Struktur Geologi Bawah Permukaan di Kawasan Semburan Lumpur Sidoarjo, Berdasarkan Penampang Ground Penetrating Radar (GPR). Jurnal Geologi Indonesia, Vol. 5 No. 3, 187-195.

[2] Mazzini, A., Nermoen, A., Krotkiewski, M., Podladchikov, Y., Planke, S., \& Svensen, H. (2009). Strike-slip faulting as a triger mechanism for overpressure release through piercement structure. Implication for the Lusi mud volcano, Indonesia, 1751-1765.

[3] Orfanidis, S. J. (2002). Electromagnetic Waves and Antennas. Piscataway: Rutgers University.

[4] R. Smyth, H., Hall, R., \& J. Nichols, G. (2008). Cenozoic volcanic arc history of East Java, Indonesia: The stratigraphic record of eruptions on an active continental margin. The Geological Society of America, 436.

[5] Reynold, J. M. (1997). An Introduction to Applied and Enviromental Geophysics. England: John Wiley and Sons, inc.

[6] Yin, H., \& Jr, R. H. (2004). Balancing and restoration of piercement structures: geologic insights from 3D kinematic models. Journal of Structural Geology, 99-114. 